\title{
Manuel Zapata Olivella, revisitado
}

El "Año de Manuel Zapata Olivella" en homenaje al centenario de su nacimiento preveía eventos de todo tipo en muchos escenarios del país. El avasallamiento del COVID-19 nos impidió, hasta ahora, esas celebraciones. Este monográfico que hoy presenta Visitas al patio cobra, entonces, otra dimensión, pues se puede concretar materialmente un proyecto pensado con motivo de la celebración que recoge textos inéditos del autor y diez artículos que buscan una renovación en la mirada acerca de su trayectoria.

La convocatoria para el presente número tuvo como eje la revisión del trabajo de Zapata Olivella en todos los aspectos de su actividad profesional, con el objetivo de contribuir al avance del conocimiento de su obra y accionar político-cultural. El propósito de este llamado a los investigadores fue, entonces, bucear en los textos menos abordados o, en su defecto, leer con perspectivas renovadas aquellos que han sido más referenciados por la crítica. La heterogeneidad de la trayectoria profesional y personal de Zapata Olivella abrió el espacio, además, a propuestas que sumaran a lo anterior otros campos de estudio vinculados a su trabajo, ya como impulsor incansable de nuevas investigaciones, ya como gestor de espacios de discusión de alcance internacional. Un aporte original sería también la observación de su recepción en el ámbito educativo para explorar la incorporación del autor hoy desde las instituciones y desde los propios estudiantes, en Colombia y fuera de sus fronteras.

Se debe reconocer que la apertura de la colección Manuel Zapata Olivella en la biblioteca de la Universidad de Vanderbilt, que guarda los archivos del autor, ha sido una bisagra en el avance de las investigaciones. El acceso a esas fuentes originales permite tanto develar el proceso que recorrió la producción del escritor previamente a sus publicaciones, como ir cosiendo puntos sueltos para avanzar en el conocimiento de una actividad prolífica como pocas a partir de una serie de documentos que obligan al análisis cruzado.

Ambos aspectos se concentran en los trabajos de Ligia Aldana y John Maddox que forman parte de los cuatro artículos del primer grupo de este volumen, El hombre de letras, dedicado a la producción literaria del escritor. "Harlem: un folio del archivo (intelectual) de Manuel Zapata Olivella" se focaliza en el tiempo-espacio de este barrio de Nueva York durante el periodo posterior al Renacimiento y analiza las relaciones y conexiones intelectuales, estéticas, políticas e ideológicas entre una parte de la vida y la obra del poeta Langston Hughes y Manuel Zapata Olivella. La relevancia vital y profesional que tuvo para Zapata este acercamiento al mundo negro de Estados Unidos en los años '40, y que había sido abordada en otro número de Visitas al patio (Maddox, 2016: 13-40), conforma, para Ligia Aldana, el germen de lo que vendría luego, tanto en materia de escritura, -creativa y ensayística- como de gestión cultural, pues es allí donde Zapata logra articular la negritud en un lugar específico -Harlem- con una condición sociocultural y política -la marginalidad. Al mismo tiempo, sin embargo, también evidenciará su contracara con la resistencia manifiesta en cuerpos simbólicos como Langston Hughes y actores políticos como Marcus Garvey. 
Valiéndose de documentación que registra los intentos de Manuel Zapata Olivella previos a la versión definitiva de Changó, el gran putas, John Maddox examina, a través de un trabajo comparativo entre el texto publicado y manuscritos hallados en la colección de Vanderbilt, la importancia que, según se desprende de esos originales, tuvo para Zapata Olivella el rol del poeta en el campo de la memoria y la liberación de los descendientes de africanos en las Américas. Para ello, el artículo "Los poemas previamente inéditos de Changó, el gran putas: el papel del poeta, las armas y las letras" toma como base las figuras de Nagó y Ngafúa, y se concentra en el tratamiento de estos personajes en Changó, en contraste con el realizado en algunos poemas inéditos de Zapata que habrían formado parte del proceso de confección de su novela mayor. Estos poemas, además, aparecen en la sección Fabulario de este número de Visitas al patio, con lo que se pone en manos de los lectores un material de gran relevancia para continuar explorando.

A este primer bloque lo abren y cierran los acercamientos a dos novelas muy poco estudiadas. En "De máscaras y demonios: criminalización, heroísmo e identidad racial en El fusilamiento del diablo”, María Alejandra Aguilar rastrea las técnicas a través de las cuales Zapata Olivella construye, en la figura de Saturio Valencia, una masculinidad negra heroica atravesada también por la conciencia de clase, y asociada, por la Ley, a la criminalidad. Desde la lectura de la autora, Valencia es recuperado por Zapata para elevarlo como parte de la genealogía heroica del Chocó, en línea, además, con el contexto de movilización incipiente en Colombia de algunos grupos negros. Por su parte, en "La literatura como realidad trascendida: narrativas de la Violencia en Detrás del rostro”, Carolina Marrugo Orozco analiza el campo cultural del momento en el que se inscribe una novela de Zapata Olivella casi ignorada por la crítica, ubicándola en el concierto del mundo artístico internacional, luego de la Segunda Guerra Mundial y en el marco de la modernización de Colombia. Detrás del rostro comparte con El fusilamiento de diablo, a pesar de los veinte años que las separan en su publicación, el juego experimental de múltiples voces y perspectivas a través de las cuales los sujetos van narrando, no solo su propia historia, sino sus vivencias más recónditas.

El segundo bloque reúne dos artículos que dan cuenta de la inmensa capacidad organizativa y el alto nivel de convocatoria de Manuel Zapata Olivella en su accionar cultural y político, y, aún más que ello, su arduo trabajo intelectual a favor de las poblaciones negras. No es casual que ambos ensayos deban situarse en la década del '70: es precisamente el momento en el que se forman en Colombia las primeras organizaciones con el propósito explícito de reclamar por y defender los derechos sociales y el reconocimiento cultural de los grupos negros, según la terminología de la época. Con ello como trasfondo, en estos años se daría forma a grupos de estudio como Soweto y a la apertura de espacios como el CIDCUN y la reactivación de otros como el Centro de Estudios Afrocolombianos (Wade, 1995, 2013; Agudelo, 2005; Pisano, 2014; Arboleda, 2018; Paschel, 2016). Es en estos dos últimos Centros de investigaciones que se concentra el artículo "Reivindicación de la 'cultura negra' y la denuncia de discriminación racial en la experiencia del Centro de Estudios Afrocolombianos y el Centro para la Investigación de la Cultura Negra (CIDCUN)". 
Lery Daniela Munar Espinosa hace un interesante análisis de este periodo al que considera embrionario del movimiento social afrocolombiano. A través de un agudo seguimiento de las agendas de lo que la autora llama espacios de referencia, el CEA y el CIDCUN, establece la importancia de distinguir entre los proyectos políticos, culturales e intelectuales y discute la lectura que desde los estudios afrocolombianos se ha hecho de ese momento inicial del movimiento.

Esta dinámica adquirida por el campo intelectual en torno a las negritudes en los años '70 se vería coronada por el Primer Congreso de la Cultura Negra de las Américas, tanto por la cantidad y calidad de sus participantes y las jugosas discusiones como por el vínculo simbólico que se establecería entre activistas e intelectuales locales y extranjeros. Muy probablemente, tal asistencia, pensando en términos del alto número de participantes estadounidenses, se vio favorecida por la novedad de este tipo de encuentro en América Latina, un espacio para conocer más de cerca, para algunos, y por descubrir, para otros, como se desprende de los intensos debates que se sucedieron durante esos tres días (Valero, 2020). Pero el otro factor de convergencia fue la figura misma de su organizador principal, Manuel Zapata Olivella. A esto último se refiere el artículo "Redes, epistemologías y acciones. Manuel Zapata Olivella en el Primer Congreso de la Cultura Negra de las Américas", de Eduard Arriaga, quien también se ha valido de documentos del autor en la colección de Vanderbilt. A través de una metodología de análisis de redes complejas, el autor concluye que, si bien es indiscutible el liderazgo de Zapata para lograr reunir a personalidades destacadas del mundo académico, cultural e intelectual de las negritudes y establecer redes con objetivos de gestión y organización de plataformas de trabajo, su centralidad solo es posible como "producto de la articulación dinámica de lógicas a diversas escalas y niveles". Esos componentes, que el autor resume en la coexistencia cultural, la solidaridad trans-nacional afectiva y la lucha decolonial por la posibilidad de existir, son los analizados a lo largo de este artículo.

El tercer bloque de artículos lo conforman dos estudios del Zapata Olivella ensayista. En términos generales, el concepto de mestizaje ha devenido un componente fundante de reflexión a la hora de hablar de cualquier texto de Zapata Olivella (ver, entre muchos otros, Viveros Vigoya, 2013; Flórez Bolívar, 2019). El contenido de la categoría, sin embargo, no siempre correrá por los mismos espacios de significación y eso es lo que busca poner en evidencia este tercer par de artículos. El primero de ellos focaliza su análisis en El hombre colombiano, un texto con una casi inexistente cantidad de estudios en su haber. El segundo realiza un seguimiento de varios ensayos publicados por el autor en diferentes momentos de su trayectoria intelectual para exponerlo como un proyecto anti-racista.

"Múltiples caras fundidas en un solo rostro. Nación y trietnicidad en El hombre colombiano" de Roxana Ponce Arrieta reconstruye el escenario dinámico en el que se movió Zapata para concebir la conformación de la nación como un proceso inseparable de la continua conformación cultural mestiza desde el inicio mismo de la conquista. La autora se pregunta acerca del poco interés que ha tenido para la crítica especializada la faceta antropológica de los estudios de Zapata, como es el caso del texto que ella estudia y, al mismo tiempo, analiza y ubica cultural, epistémica y políticamente 
la noción de nación emergente de El hombre colombiano. Por su lado, "El proyecto anti-racista del mestizaje. Manuel Zapata Olivella”, de Carlos Alberto Valderrama Rentería también aborda el mestizaje a partir de entenderlo "como un terreno de confrontación política e ideológica entre regímenes de conocimiento y poder que se disputan la hegemonía y el control discursivo sobre su significado". En este sentido, el artículo abre el espectro del acercamiento al mestizaje buscando demostrar cómo Zapata lo exhibe como una narrativa anti-racista en la política cultural del folklore negro que despliega en sus ensayos, entre 1945 y 1960. Resulta relevante, al mismo tiempo, la serie de contradicciones que, en su conclusión, encuentra Carlos Valderrama en algunas de aquellas reflexiones y que deja un amplio espacio de posibilidades para futuros análisis.

Los dos últimos artículos conforman un original aporte a este monográfico en tanto nos permiten escudriñar, a cien años del nacimiento de Zapata Olivella, algunos aspectos de la recepción de su obra por parte de plataformas educativas de dos ámbitos alejados entre sí: Colombia y Senegal. En "La transversalidad de la obra de Manuel Zapata Olivella en el currículum de la Cátedra de Estudios Afrocolombianos", Alejandra Rengifo va tras las causas posibles por las cuales la Cátedra de Estudios Afrocolombianos no incorpora de manera adecuada, según su propia apreciación, la obra de Zapata Olivella en el currículo de etnoeducación colombiana. La autora analiza de qué manera la transversalidad de sus producciones, en tanto portadoras de conocimiento histórico, literario, antropológico, folklórico, lo convierten en lo que debería ser un insumo básico para la adquisición de conocimiento a nivel educativo. Por su parte, y cerrando este recorrido, Sébastien Lefèvre nos entrega "Changó, el gran putas leído, analizado y vivido desde las costas africanas. El caso de clases de literatura y civilización afrodiaspóricas en Senegal". Acceder desde el testimonio del mismo profesor y sus estudiantes a la experiencia de lo que significa enseñar/apre(he)nder literatura afrolatinoamericana, en este caso concentrada en la novela máxima de Zapata Olivella, en un ámbito de desconocimiento casi absoluto de la misma, es una puerta abierta para comprender muchos otros aspectos que rebasan lo meramente literario. Aquella transversalidad de la obra de Zapata de la que habla Alejandra Rengifo en el artículo referenciado anteriormente, se incrementa en este caso a una revisión de estos estudiantes africanos con respecto a sus propias miradas sobre la diáspora africana en las Américas y hasta de su propia historia cultural.

Finalmente, en Fabulario, como ya se adelantó, se reunieron tres grupos de poemas rescatados de los archivos que dejó Manuel Zapata tras su muerte y que, según todo lo indica, habrían sido parte de los intentos del autor antes de darle la forma definitiva a Changó, el gran putas.

Silvia Valero

Editora 


\section{BIBLIOGRAFÍA}

Agudelo, C. (2005). Multiculturalismo en Colombia: política, exclusión e inclusión de poblaciones negras. Medellín: La Carreta, IEPRI, IRD, ICANH.

Arboleda, S. (2018). Le han florecido nuevas estrellas al cielo: Suficiencias íntimas y clandestinización del pensamiento afrocolombiano. Cali: Poemia.

Flórez, F. (2019). Celebrando y redefiniendo el mestizaje: raza y nación durante la República Liberal, Colombia, 1930-1946. Memorias: Revista Digital de Historia y Arqueología desde el Caribe colombiano (enero-abril), 93-116.

Maddox, J. (2016) Una falla geológica de fallas raciales: el Sur norteamericano en Piri Thomas y Manuel Zapata Olivella. Visitas al patio (10), 13-40. doi.org/10.32997/20270585-vol.0-num.10-2016-1786

Paschel, T. (2016). Becoming Black Political Subjects: Movements and Ethno-Racial Rights in Colombia and Brazil. Princeton, NJ: Princeton University Press.

Pisano, P. (2014). Movilidad social e identidad "negra" en la segunda mitad del siglo XX. Anuario Colombiano de Historia Social y de la Cultura, 41(1), 179-199.

Valero, S. (2020). "Los negros se toman la palabra”. Primer Congreso de la Cultura Negra de las Américas: debates al interior de las comisiones y plenarias. Bogotá-Cartagena: Pontificia Universidad Javeriana-Universidad de Cartagena-CEA.

Viveros Vigoya, M. (2013). Mestizaje, trietnicidad e identidad negra en la obra de Manuel Zapata Olivella. En Restrepo, Eduardo (Ed.) Estudios afrocolombianos hoy: aportes a un campo transdisciplinario, (pp. 87-103). Popayán: Universidad del Cauca.

Wade, P. (2013). Definiendo la negridad en Colombia. En Restrepo, Eduardo (Ed.) Estudios afrocolombianos hoy: aportes a un campo transdisciplinario, (pp. 21-41). Popayán: Universidad del Cauca.

Wade, P. (1995). The Cultural Politics of Blackness in Colombia. American Ethnologist, 22(2), 341-357. 